\title{
A IMPORTÂNCIA DA CIÊNCIA NA EDUCAÇÃO ESCOLAR: REFLEXÕES DA TEORIA HISTÓRICO-CULTURAL E DA PEDAGOGIA HISTÓRICO-CRÍTICA
}

\author{
Isis Azevedo Chaves ${ }^{1}$, Rafael Rossi ${ }^{2}$ \\ ${ }^{1}$ Mestranda em Educação na Faculdade de Educação e no Programa de Pós-Graduação em Educação - PPGEDU - da \\ Universidade Federal do Mato Grosso do Sul - UFMS. Auxiliar em administração da Universidade Federal de Mato \\ Grosso do Sul - UFMS. ORCID iD: https://orcid.org/0000-0003-3199-563X. E-mail: isis.capelania@hotmail.com \\ ${ }^{2}$ Doutor e pós-doutor em Educação pela Universidade Estadual Paulista - UNESP. Professor e orientador na Faculdade \\ de Educação e no Programa de Pós-Graduação em Educação - PPGEDU - da Universidade Federal do Mato Grosso do \\ Sul - UFMS. ORCID iD: https://orcid.org/0000-0001-8544-3756. E-mail: $\underline{\text { r.rossi@ufms.br }}$
}

\section{RESUMO}

Este texto é um instrumento por meio do qual demonstramos a origem, a natureza e a função social do conhecimento científico e a sua importância histórica na educação escolar a partir das contribuições da perspectiva ontológica marxiana, a pedagogia histórico-crítica e a teoria histórico-cultural. 0 objetivo é demonstrar, tendo como base o processo histórico da autoconstrução humana, a essência da ciência, bem como a necessidade de cada vez mais a educação escolar defendê-la. Nossa intenção é refletir sobre a constituição e o potencial humanizador dos conhecimentos científicos no ambiente escolar. Ressaltamos que esses elementos são essenciais para o desenvolvimento do psiquismo humano e sua apropriação requer a tarefa docente, de pesquisa, ensino e aprendizagem, no espaço-tempo escolares.

Palavras-chave: Conhecimento científico. Teoria Histórico-Cultural. Pedagogia Histórico-Crítica.

\section{THE IMPORTANCE OF SCIENCE IN SCHOOL EDUCATION: REFLECTIONS OF HISTORICAL-CULTURAL THEORY AND HISTORICAL-CRITICAL PEDAGOGY}

\section{ABSTRACT}

This text is an instrument through which we demonstrate the origin, nature and social function of scientific knowledge and its historical importance in school education from the contributions of the marxian ontological perspective, historical-critical pedagogy and historical-cultural theory. The objective is to demonstrate, based on the historical process of human self-construction, the essence of science, as well as the need for more and more school education to defend it. Our intention is to reflect on the constitution and humanizing potential of scientific knowledge in the school environment. We emphasize that these elements are essential for the development of the human psyche and their appropriation requires the teaching, research, teaching and learning task in the school space-time.

Keywords: Scientific knowledge. Historical-Cultural Theory. Historical-Critical Pedagogy

\section{LA IMPORTANCIA DE LA CIENCIA EN LA EDUCACIÓN ESCOLAR: REFLEXIONES DE LA TEORÍA HISTÓRICO- CULTURAL Y PEDAGOGÍA HISTÓRICO-CRÍTICA}

\section{RESUMEN}

Este texto es un instrumento a través del cual demostramos el origen, naturaleza y función social del conocimiento científico y su importancia histórica en la educación escolar desde los aportes de la perspectiva ontológica marxista, la pedagogía histórico-crítica y la teoría histórico-cultural. El objetivo es demostrar, a partir del proceso histórico de autoconstrucción humana, la esencia de la ciencia, así como la necesidad de una educación cada vez más escolar para defenderla. Nuestra intención es reflexionar sobre la constitución y el potencial humanizador de la ciencia. conocimiento en el entorno escolar. Destacamos que estos elementos son fundamentales para el desarrollo de la psique humana y su apropiación requiere la tarea de enseñanza, investigación, enseñanza y aprendizaje en el espacio-tiempo escolar.

Palabras clave: Conocimiento científico. Teoría Histórico-Cultural. Pedagogía histórico-crítica. 


\section{INTRODUÇÃO}

Este artigo integra a pesquisa de mestrado em andamento no Programa de PósGraduação em Educação da Universidade Federal de Mato Grosso do Sul (PPGEDU/UFMS), campus de Campo Grande - MS e os estudos que ocorrem no interior do grupo de pesquisa "Fundamentos da Educação" - GEFE, vinculado à Faculdade de Educação da mesma instituição. Pretendemos explicitar e refletir sobre a relevância dos conhecimentos científicos na educação escolar, haja vista que esses elementos possibilitam o desenvolvimento intelectual e cultural dos indivíduos. Para tanto, propomos uma articulação entre os pressupostos da teoria histórico-cultural e os fundamentos da pedagogia histórico-crítica, sendo esta, a concepção pedagógica e educacional que norteia o trabalho em curso.

Essa visão defende que os conteúdos ensinados na educação escolar devem ser relevantes e colaborem para a capacidade de compreensão crítica e mudança da concepção de mundo, possibilitando a transformação social no sentido da emancipação humana (SAVIANI, 2011). Concepção de mundo aqui compreendida como a maneira individual de entender a natureza e constituição humanas, a coletividade, as perspectivas de futuro tendo em vista que esta percepção é fator participante dos critérios que o indivíduo se apropria para estabelecer as suas relações em sociedade.

Importante ponderar que nas últimas décadas a educação escolar, em todos os níveis, tem sofrido um processo de esvaziamento com relação à defesa dos conhecimentos científicos (DUARTE, 2016). Compreendemos que as ciências (exatas, da natureza e sociais) são fontes inestimáveis de conhecimento por permitirem uma compreensão profunda da realidade, seja ela natural ou social. Como iremos demonstrar, o conhecimento científico possui sua função social a partir da capacidade humana em efetivar atos de trabalho, ou seja, a partir do momento em que a humanidade passa a transformar a natureza de modo consciente e intencional para $o$ atendimento de uma necessidade real.

Não estamos resumindo a ciência ao trabalho. Por outro lado, entendemos que a ciência é um complexo social que se desenvolveu ao longo da história. Partir dos atos de trabalho para compreender a função social da ciência em conhecer a realidade como ela é em sua essência é um procedimento de ordem ontometodológica. Isto significa que não estamos partindo de premissas ou de conceitos criados a priori. O nosso ponto de partida é o processo de autoconstrução humana. O método, na perspectiva ontológica marxiana, não é, pois, um conjunto de procedimentos que o pesquisador "encaixa" sobre o real. O método é subordinado ao próprio objeto, ou seja, trata-se de compreender o objeto em questão - em nosso caso o conhecimento científico - tendo como base o processo histórico real e a épica trajetória do gênero humano, sempre levando em consideração as múltiplas interações entre os complexos sociais enquanto totalidade.

Para desenvolver este artigo, partimos das contribuições de Saviani (2011); Martins (2013, 2016); Duarte $(2013,2016)$; Duarte e Saviani (2019); Lukács (2013) e Rossi e Rossi (2019). Os autores foram selecionados considerando: as contribuições para o entendimento da pedagogia histórico-crítica, as fundamentações da teoria histórico-cultural e os aspectos ontológicos, históricos e essenciais do processo de autoconstrução humana.

Quanto a base para as reflexões consonantes, optamos pelas contribuições de Lev Semionovitch Vigotski ${ }^{1}$ (1991, 2001), autor da teoria histórico-cultural e Alexis Nikolaevich Leontiev (2004), considerando as suas elaborações que compreendem a apropriação e aprendizagem constituídas pelos elementos culturais, como estímulo ao desenvolvimento das capacidades intelectuais tão-somente humanas.

Tanto a pedagogia histórico-crítica quanto a teoria histórico-cultural compreendem que o homem ${ }^{2}$ não nasce com a capacidade intelectual desenvolvida, e sim, com faculdades mentais suscetíveis a ativação/expansão que, por meio das relações sociais e do trabalho educativo são despertadas, ativadas, aumentadas e reproduzidas socialmente. Para essas teorias, a educação escolar é uma dimensão social cuja função é sistematizar e socializar a produção humana adquirida ao longo dos anos mediante as experiências sociais. A escola representa a possibilidade de apropriação individual do

\footnotetext{
${ }^{1}$ Optamos pela grafia Vigotski no texto, considerando ser a mais comum na língua portuguesa.

${ }^{2}$ Escolhemos a referência homem para o ser humanizado, social, de forma genérica, independente de sexo.
} 
patrimônio material e espiritual ${ }^{3}$ que já foi produzido/apropriado coletivamente, assim dizendo, a oportunidade de incorporação da cultura humana. Nessa direção, Saviani (2011) afirma que:

[...] o objeto da educação
diz respeito, de um lado, à
identificação dos
elementos culturais que
precisam ser assimilados
pelos indivíduos da
espécie humana para que
eles se tornem humanos
e, de outro lado e
concomitantemente, à
descoberta das formas
mais adequadas para
atingir esse objetivo
(SAVIANI, 2011, p. 13,
grifos nossos).

A educação a partir de um ponto de vista humano-genérico, quer dizer, que considera as legítimas necessidades de desenvolvimento qualitativo humano, deve ser planejada e executada utilizando os conteúdos culturais elaborados pela humanidade que possibilitam a efetivação dessa finalidade. Esses elementos culturais devem ser transmitidos e apropriados na escola, tendo em vista que "[...] o trabalho educativo é o ato de produzir, direta e intencionalmente, em cada indivíduo singular, a humanidade que é produzida histórica e coletivamente pelo conjunto dos homens" (SAVIANI, 2011, p. 13). Com essa constatação compreendemos que o homem é humanizado desde o seu nascimento até os mais complexos processos educacionais que acontecem em sua vida, durante todo o seu tempo de existência.

O ser humano não nasce ser humano. Nós nascemos, biologicamente, membros da espécie humana. Todavia, para desenvolvermos nossa humanidade precisamos de múltiplas interações sociais e de processos de apropriação da cultura. "Podemos dizer que cada indivíduo aprende a ser um homem. $O$ que a natureza lhe dá quando nasce não lhe basta para viver em sociedade. É-lhe ainda preciso adquirir o que foi alcançado no decurso do desenvolvimento histórico da sociedade humana" (LEONTIEV, 2004 , p. 285). Em suma, ninguém nasce predestinado à miséria, ao fracasso escolar ou a

\footnotetext{
${ }^{3}$ Utilizamos a palavra espiritual especificamente para a atividade humana intelectual, não material.
}

comportamentos que transgridam as regras da vida em sociedade. O comportamento humano é apreendido nas relações sociais.

Defendemos a ideia de que a humanização ${ }^{4}$ ocorre dentro de um processo histórico, coletivo, determinado por apropriações individuais, culturais, dos determinantes sociais. Por outra vertente, a decorrência não é igualmente favorável quando há ausência de elementos constitutivos, que desenvolvem as capacidades intelectuais humanas e privação de convivência social. Nesse aspecto, os resultados podem ser extremamente prejudiciais para o indivíduo ao avaliarmos o desenvolvimento intelectual e cultural, a humanização. Um bom exemplo a citarmos aqui, é a história de Oxana Malaya ${ }^{5}$, uma criança ucraniana, cuja convivência com os cães durante anos, impediu a evolução qualitativa de suas funções psicológicas, considerando que ela apreendeu mais do comportamento animal do que humano.

Tendo em vista a necessidade de apropriações e transmissões no processo de humanização, os seres humanos passam os seus dias em constante busca coletiva por novos conhecimentos, habilidades, valores etc. Nesse sentido, concordamos que "o caminho do objeto até a criança e desta até o objeto passa através de outra pessoa. Essa estrutura humana complexa é o produto de um processo de desenvolvimento profundamente enraizado nas ligações entre história individual e história social (VIGOTSKI, 1991, p. 24). Em compreensão da relevância do papel do professor e da educação escolar, Saviani considera que:

$$
\begin{aligned}
& {[\ldots . .] \text { a tarefa a que se }} \\
& \text { propõe a pedagogia }
\end{aligned}
$$

\footnotetext{
${ }^{4}$ Humanização aqui foi compreendida quanto processo de evolução intelectual, social, qualitativa, do ser humano.

${ }^{5}$ Oxana Malaya, começou a conviver com os cães aos 3 anos de idade, após ser abandonada pelos pais alcoólatras. Como não tinha interações com humanos, a falta de contato fez com que esquecesse que era humana; todos os seus gestos eram copiados dos animais. Uma vez que os cachorros não respondiam com palavras, ela foi deixando de lado a sintaxe humana, e a substituiu por latidos. Andava de quatro na grama da fazenda onde morava, arqueada, correndo desse jeito e com a língua de fora. Malaya foi resgatada após 5 anos, mas os estragos já eram grandes e foi internada em clínica psiquiátrica. Anos após o retorno a convivência social, especialistas acreditam que ela não irá se desenvolver intelectualmente diante dos anos perdidos enquanto vivia com os cachorros. Porém, tendo em mente outros casos de crianças selvagens, o saldo da vida da ucraniana pode ser considerado positivo. Aos 36 anos de idade, ela ainda cuida de vacas e da fazenda que a acolheu de verdade. Disponível em: https://aventurasnahistoria.uol.com.br/noticias/reportagem/renega da-pelos-pais-adotada-pelos-caes-a-triste-saga-de-oxana-malaya-amenina-selvagem.phtml. Acesso em: 20 set. 2020
} 
histórico-crítica em relação à educação escolar implica: a) Identificação das formas mais desenvolvidas em que se expressa o saber objetivo produzido historicamente, reconhecendo as condições de sua produção e compreendendo as suas principais manifestações, bem como as tendências atuais de transformação. b) Conversão do saber objetivo em saber escolar, de modo que se torne assimilável pelos alunos no espaço e tempo escolares. c) Provimento dos meios necessários para que os alunos não apenas assimilem o saber objetivo enquanto resultado, mas apreendam - processo de sua produção, bem como as tendências de sua transformação (SAVIANI, 2011, p.9).

Este posicionamento evidencia o compromisso da pedagogia histórico-crítica em resgatar a valorização da escola e dos conteúdos científicos, artísticos e filosóficos, defendendo o processo educativo que aponta para as ações ontológicas e desenvolvimento máximo da capacidade intelectual dos alunos para uma vida em sociedade.

Temos clareza de que ainda no interior do capitalismo é uma impossibilidade real a defesa ampla e absoluta da ciência em toda a educação escolar. Todavia, chamamos a atenção para a compreensão histórica e ontológica do conhecimento científico, bem como sua importância no desenvolvimento intelectual dos alunos.

Para alcançarmos o objetivo proposto, o texto foi dividido em duas partes, além da Introdução e Considerações finais. Na primeira parte, refletimos sobre a atividade humana, isto é, o trabalho, como categoria que institui o ser social e produtora de conhecimento científico. $\mathrm{Na}$ segunda parte, apresentamos como a apropriação do conhecimento científico participa do processo de humanização na educação escolar. Por fim, nossas considerações a respeito desse tema de total relevância para a formação e transformação da humanidade.

\section{TRABALHO E CONHECIMENTO CIENTÍFICO}

Conforme assinalamos brevemente na introdução, para compreender a gênese e a particularidade da dimensão científica não iremos partir de premissas dadas a priori ou de conceitos e categorias criados de antemão. Se assim estivéssemos procedendo, estaríamos colocando a nossa subjetividade para dizer o que a ciência é. Seria, nesse caso, uma abordagem gnosiológica, ou seja, uma perspectiva em que o sujeito possui a predominância no processo investigativo.

Todavia, trabalhamos a partir da perspectiva ontológica marxiana e isso implica na regência do objeto para a compreensão dos fenômenos e/ou processos estudados. A subjetividade humana certamente é importantíssima na pesquisa, entretanto, numa perspectiva ontológica, ela deve estar subordinada ao objeto. Isto significa que devemos mobilizar a nossa subjetividade no sentido de "traduzir", "desvendar", "descobrir" e "revelar" o movimento próprio e essencial do objeto em si mesmo.

Dessa forma, nosso ponto de partida é o processo de autoconstrução humana a partir dos atos de trabalho, ou seja, da transformação consciente e intencional da natureza para o atendimento de uma necessidade igualmente real. Não se trata, como já afirmamos, de simplificar tudo apenas aos atos de trabalho. Por outro lado: trata-se de compreender a gênese dos complexos sociais a partir da categoria que funda o ser social: o trabalho.

Entendemos que o processo histórico e ontológico possui informações fulcrais para a compreensão da essência e formação do ser humano e que "para expor em termos ontológicos as categorias específicas do ser social, seu desenvolvimento a partir das formas de ser precedentes, sua articulação com estas, sua fundamentação nelas, sua distinção em relação a elas, é preciso começar essa tentativa com a análise do trabalho" (LUKÁCS, 2013, p. 33). Só podemos compreender as categorias características do ser social, por exemplo, a reprodução social, a ciência e a educação, se analisarmos a origem da totalidade social: o trabalho. Sendo assim, começamos esta parte com a reflexão sobre os atos de trabalho, uma 
vez que é a partir dessa prática que os indivíduos começam a se formar enquanto seres humanos.

O procedimento metodológico de Lukács (2013), portanto, parte do rastreamento do processo de surgimento do ser social, ou seja, da humanidade. Trata-se, em verdade, da premissa à fidelidade ao processo real. Podemos perceber, com isso, a radical historicidade da perspectiva lukacsiana de ordem ontológica em seu pensamento maduro. A partir do trabalho há um efetivo "pôr teleológico", o que indica a capacidade humana em refletir na consciência à luz das possibilidades do real, os obstáculos e as oportunidades concretas para que a finalidade idealmente traçada possa ser atingida.

Tanto a pedagogia histórico-crítica quanto a teoria histórico-cultural compreendem que o trabalho ${ }^{6}$ é uma categoria exclusivamente humana e fundante do ser social, humano. 0 entendimento da relação da atividade do homem com a natureza é fundamental para a compreensão do processo de autoconstrução humana. Em outras palavras, o homem trabalha transformando a natureza ${ }^{7}$ ao mesmo tempo que transforma a sua própria natureza ${ }^{8}$ (DUARTE, 2019; SAVIANI, 2011).

Concomitantemente, no processo de transformação da natureza do e pelo homem, ocorre um salto ontológico e o ser natural, orgânico, simplesmente biológico, incorpora alterações constitutivas expressivas e se eleva ao grau de social, humano. $O$ salto é imperativo para a quebra do ciclo da "reposição/reprodução do mesmo", que limitava o processo evolutivo do ser, cujas características eram estabelecidas somente biologicamente, quer dizer, por transferência genética. Lukács (2013) prossegue expondo que o ser social continua com suas características biológicas, após o salto e todas as mudanças ontológicas significativas. Independente do quanto sofra alterações qualitativas, sua constituição biológica permanece inalterável em qualquer estágio

\footnotetext{
${ }^{6}$ Trabalho aqui foi compreendido como atividade humana de transformação da natureza para a produção das condições materiais da existência social.

${ }^{7}$ Importante entender que natureza aqui deve ser compreendida como o total dos elementos naturais que podem ser transformados pela atividade humana, isto é, pelos atos de trabalho.

${ }^{8}$ Natureza aqui foi compreendida quanto a constituição ontológica e como base do processo de reprodução humana. A maneira de pensar, agir, de viver em sociedade.

${ }^{9}$ É preciso, pois, ter sempre presente que se trata de uma transição à maneira de um salto - ontologicamente necessário - de um nível de ser a outro, qualitativamente diferente. (LUKÁCS, 2013, p.34)
}

evolutivo e dimensão social que ele esteja inserido.

O trabalho permite surgir uma articulação inteiramente nova entre consciência e realidade. A partir de uma necessidade real e existente, a consciência humana deverá amealhar conhecimentos e habilidades, bem como compreender os limites e as possibilidades que a realidade oferece para que aquele objetivo inicial possa ser alcançado. Percebam que, no entendimento de Lukács (2013), a consciência possui a sua importância em compreender, mesmo que de modo sempre aproximado, a realidade como ela é em si mesma, entretanto, os limites e as oportunidades são dados pela própria realidade e não pela consciência. Caso a consciência queira deturpar a realidade, fantasiar sobre ela ou colocar os seus desejos acima daquilo que o real apresenta, então, nesse caso, a finalidade inicial (saciar a fome, por exemplo) não será atingida.

Este entendimento ontológico é extremamente importante para a compreensão de que não são as transformações biológicas que determinam o desenvolvimento sócio-histórico do homem e da humanidade. A formação e transformação do ser social, não dependem exclusivamente das mudanças biológicas, mas das interações entre os homens, do social. Lukács (2013) irá distinguir entre o pôr teleológico primário e os pores teleológicos secundários. Os primários indicam a relação entre o homem e a natureza que ocorre no trabalho e os secundários indicam a relação dos homens entre si, como ocorre, por exemplo, na gênese da dimensão educativa. Leontiev (2004) possui também uma reflexão importante a este respeito:

O indivíduo é colocado diante de uma imensidade de riquezas acumuladas ao longo dos séculos por inumeráveis gerações de homens, os únicos seres, no nosso planeta, que são criadores. As gerações humanas morrem e sucedem-se, mas aquilo que criaram passa às gerações seguintes que multiplicam e aperfeiçoam pelo trabalho e pela luta as riquezas que thes foram transmitidas e "passam o testemunho" do desenvolvimento da 
humanidade (LEONTIEV, 2004, p. 285)

Toda produção intencional realizada pelo homem para suprir suas necessidades de sobrevivência físicas, biológicas e sociais, o mesmo autor conceitua como cultura. Cultura no sentido de tudo que o homem já criou, o conhecimento humano, científico, tudo que abarca a vida humana e possibilita que o homem seja social. Partindo desse pressuposto, compreendemos que a cultura é o principal efeito produzido pelo trabalho. Todos estes conhecimentos, por sua vez, permitirão novas transformações da natureza do e pelo homem, de modo elaborado e, resumidamente, tem início assim a história humana (LEONTIEV, 2004).

É uma decorrência incontornável dos atos de trabalho a geração de conhecimentos, habilidades, técnicas, valores e ideias. Toda esta cultura humana - em seu sentido amplo permitirá uma série amplíssima de novas atividades laborativas distintas daquelas iniciais. As novas gerações, por seu turno, precisarão se apropriar destes elementos culturais para se formarem enquanto membros do gênero humano. Aqui reside, portanto, a gênese e a função social da dimensão que costumamos chamar de educação: possibilitar a transmissão e a assimilação dos elementos da cultura humana. Os conhecimentos que serão transmitidos, a qualidade do processo de apropriação e objetivação são questões que só podem ser respondidas à luz das possibilidades e dos obstáculos que a totalidade social determina.

Se o conhecimento não
transformasse as pessoas
e não transformasse a
sociedade, ele não
passaria de uma massa
morta de informações,
palavras e ideias. Mas o
conhecimento é atividade
humana condensada e
sua socialização traz à
vida a atividade que ali se
encontra em estado
latente. Essa atividade, no
processo de sua
apropriação pelos
indivíduos, produz nestes
o movimento do intelecto,
dos sentimentos e da
corporeidade, em outras
palavras, põe em
movimento o humano

(DUARTE, 2016, p. 34, grifos nossos).

O trecho de Duarte (2016) é importante, pois nos ajuda a compreender a importância do conhecimento clássico, ou seja, dos conhecimentos que se firmaram na história humana por terem sido capazes de sistematizar a atividade humana passada e, por isso mesmo, alcançaram a potencialidade de apreensão do real para além de suas aparências. No debate educacional é muito comum posturas que compreendem a pedagogia histórico-crítica como uma pedagogia inerentemente conteudista, sendo que este adjetivo é utilizado em tom, de modo geral, pejorativo. O equívoco dessas posturas é compreender os conhecimentos científicos, no caso nosso aqui em tela, como algo "morto" e que não estimularia a criatividade e autonomia dos alunos. Justamente o contrário ocorre: quando os alunos, nas escolas e universidades, possuem a oportunidade de se apropriarem dos clássicos das ciências, a sua criatividade e autonomia intelectual se desenvolvem, já que é a partir deste processo rico de apropriação que terão as bases para a elaboração de outras objetivações intelectuais em diversas áreas. Podemos mesmo afirmar que quanto mais ricas forem as apropriações intelectuais que os indivíduos tiverem a oportunidade de realizar, mais chances e possibilidades terão de elaborarem novas objetivações.

Conhecer não diz respeito apenas a saber da existência, mas principalmente a incorporação de informações suficientes sobre o objeto para que ocorra uma mudança na forma de pensar sobre ele e tudo que se relaciona com ele (o objeto). Por isso, o conhecimento que reproduz opiniões, experiências pessoais e crenças não é de interesse da pedagogia histórico crítica quanto à finalidade ontologicamente posta que é o desenvolvimento qualitativo considerando as legítimas necessidades formativas humanas na educação escolar. O conhecimento implica a articulação entre informações, a compreensão histórica dos fenômenos, a crítica das teorias e dos discursos à luz do processo histórico real e, ainda, o entendimento das múltiplas mediações que se estabelecem entre as dimensões sociais e a totalidade.

A partir do trabalho, são produzidos novos elementos culturais, conhecimentos, habilidades, ideias: o germe do conhecimento 
científico, que se torna mais desenvolvido a cada atividade humana, em outros termos, a cada trabalho efetivado. Nosso esforço é no sentido de compreendermos a importância do conhecimento científico que, para a pedagogia histórico-crítica e a teoria histórico-cultural, é o conhecimento teórico que possui respaldo na realidade, que não diz respeito às camadas mais superficiais do real, mas sim em seu movimento essencial (LEONTIEV, 2004; MARTINS, 2016).

O plano das aparências, do senso comum, é insuficiente para uma compreensão sólida e profunda da própria realidade (ROSSI; ROSSI, 2019). Para entendermos o que é a realidade, a sociedade, a natureza e a constituição dos seres humanos, considerando que essa compreensão depende da nossa concepção de mundo, precisamos ir além da superficialidade (DUARTE, 2013) haja vista que a revelação do que é real tem papel fundamental na transformação da nossa existência como ser social.

No impulso investigativo da subjetividade inerente ao trabalho, com vistas à captura do objeto como ele realmente é, na sua essência, está a gênese ontológica da ciência. “É, portanto, a partir da tendência intrínseca à busca dos meios durante a preparação e execução do processo de trabalho que se desenvolve 0 pensamento cientificamente orientado" (LUKÁCS, 2013 , p. 46) que consiste em perceber e incorporar à memória o objeto quanto a sua essência, não apenas a aparência. A aparência é apenas o ponto de partida, mas não é o ponto de chegada. Uma escola ou universidade, portanto, que não valoriza as ciências, acaba ficando restrita a leituras e análises rasas da realidade. A função social do conhecimento científico (ciências da natureza, exatas e humanas) é a compreensão, sempre aproximada, profunda e o mais correta possível da realidade social e natural.

É importante que a subjetividade do pesquisador não coloque os seus anseios, os seus desejos e as suas vontades acima do imperativo de compreensão da realidade e do objeto como eles são em sua essência ao longo do processo histórico. A ciência nos mostra aquilo que realmente é, sem interferência dos julgamentos e permite a expansão da capacidade humana de dominar sobre fatos que existem, mas ainda são desconhecidos por nós. Somente o pensamento cientificamente orientado pode compreender a interação entre as dimensões sociais de forma objetiva e mais próxima da realidade.
A ciência, portanto, implica a compreensão correta e mais aproximada possível da essência da realidade e seus fenômenos. Partimos do processo de trabalho, pois compreendemos, na esteira de Lukács (2013), que o entendimento das dimensões sociais precisa partir do processo de autoconstrução humana e não a partir de premissas ou concepções definidas a priori. O conhecimento científico, portanto, possui uma íntima relação com a efetivação dos atos de trabalho e irá permitir compreender a realidade em seu próprio movimento, desenvolvimento e estrutura. Por isso a ciência é fundamental em ser defendida na educação escolar como iremos aprofundar no próximo item.

\section{A CIÊNCIA E SUA RELEVÂNCIA NA EDUCAÇÃO ESCOLAR}

Para compreender a importância da ciência na educação escolar é significativo partir de um entendimento estrutural:

O trabalho educativo é um
ato de produção direta e
intencional. Produção do
quê? Produção, em cada
indivíduo, da humanidade
que vem sendo produzida
historicamente. O que o
trabalho educativo
produz, portanto, é a
humanização do indivíduo,
a transformação do
indivíduo em indivíduo
humano (DUARTE, 2013,
p. 64).

Uma reflexão que pode ser elaborada a partir desse trecho de Duarte (2013) é com relação a responsabilidade intelectual e social dos professores. Questões como: quais conhecimentos estão sendo transmitidos? Aqueles conhecimentos clássicos e mais elaborados pela humanidade? Ou, por outro lado, está se transmitindo conhecimentos populares, superficiais e presos às aparências do real? Em qual orientação está ocorrendo esse processo educativo? Trata-se de uma postura crítica, histórica e ontológica? Ou a partir do idealismo em seus mais diversos matizes? Análise

Todas essas indagações são relevantes para a pesquisa educacional e para a tarefa docente, pois implicam o raciocínio de pensar nos vínculos das escolas com a sociedade, com a história, dos indivíduos entre si, dos indivíduos 
com as classes sociais, dos indivíduos com o conhecimento etc. A tarefa docente, portanto, precisa refletir com relação à defesa integral do ser humano em todas as suas dimensões ou, por outro lado, a sua deturpação e alienação a partir dos interesses mercadológicos. Isso, por sua vez, se relaciona com o nível e a qualidade dos conhecimentos que estão sendo transmitidos e assimilados na educação escolar, bem como a orientação deste processo.

Quando debatemos o que ensinar na escola, a nossa intenção é advogar a favor dos elementos que possibilitem o desenvolvimento máximo da capacidade do gênero humano e de uma visão de mundo definida favorável ao conhecimento da realidade mais autêntica possível (SAVIANI, 2011). O ensino deve ser pautado nas necessidades de formação de conceitos, valores, conhecimentos humanos com vistas ao horizonte, que, para a pedagogia histórico-crítica é a capacitação do indivíduo para construir a própria constituição quanto ser social, a autoconstrução humana e transformação da sociedade.

[...] O aprendizado
adequadamente
organizado resulta em
desenvolvimento e põe
em movimento vários
processos que, de outra
forma, seriam impossíveis
de acontecer. O
aprendizado é um aspecto
necessário e universal do
processo de
desenvolvimento das
funções [eminentemente
humanas] culturalmente
organizadas (VIGOTSKI,
1991, p. 101).

O desenvolvimento das funções psicológicas superiores está condicionado a efetivação da aprendizagem, que, no que the concerne, depende das apropriações dos conhecimentos científicos. Quanto mais elevado esse desenvolvimento, mais humanizado se torna o indivíduo, distanciando cada vez mais dos animais (LEONTIEV, 2004). A própria história confirma este posicionamento de Leontiev (2004): Leonardo Da Vinci, por exemplo, só pôde desenvolver tantas invenções e projetos fantásticos em seu tempo, pois passou por um longo processo de apropriação de técnicas, habilidades e conhecimentos altamente desenvolvidos naquele momento. Além disso, tratava-se de uma sociedade em profunda transformação social e econômica. Portanto, quanto mais ricas forem as apropriações intelectuais e científicas que os indivíduos realizarem, mais possibilidades terão de novas objetivações em nível elaborado.

Esse entendimento aponta para a relevância em distinguir os elementos fundamentais que precisam ser assimilados pelos indivíduos atendendo às profundas e autênticas necessidades formativas humanas. Nesse sentido, estamos ponderando sobre os conteúdos mais elaborados que a humanidade já produziu: os conhecimentos científicos no grau máximo da evolução da humanidade.

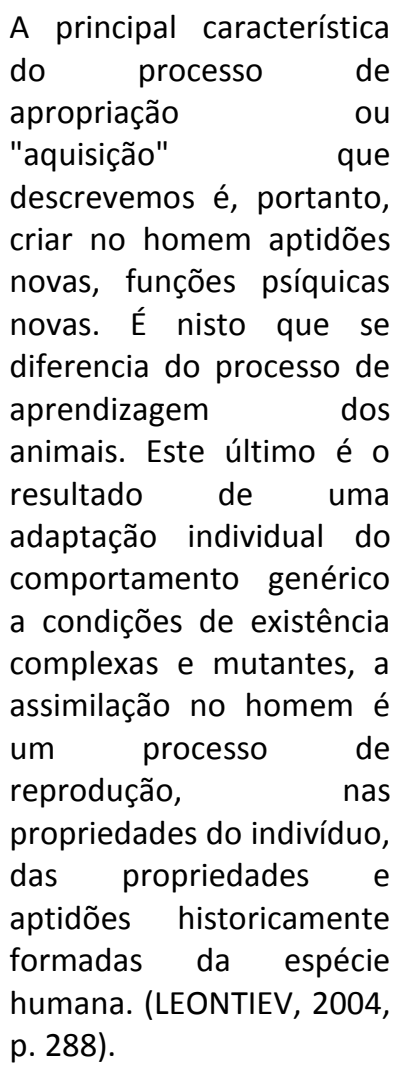

Conforme já
compreendemos que os conhecimentos
elaborados e historicamente acumulados pela humanidade, contém vida intelectual e cultural. Significa que carregam em seu interior determinantes constitutivos humanos que, quando ativados, favorecem o processo de formação/transformação do ser social. Todas as inovações que na atualidade estamos assistindo com relação ao desenvolvimento de vacinas contra a COVID-19, por exemplo, só puderam ser efetivadas, pois os cientistas se apropriaram dos conhecimentos científicos necessários para compreenderem o desenvolvimento desse vírus 
da forma mais aproximada e correta possível. Trata-se, nesse exemplo, de dois quesitos importantes para nosso debate e que chamamos a atenção: a perspectiva ontológica em compreender o objeto como ele é em sua essência e desenvolvimento e, também, o processo de apropriação de conhecimentos elaborados para a produção de novas objetivações.

Nesse sentido, a educação escolar mesmo com todas as dificuldades que atravessa ainda é o espaço em que os trabalhadores e seus filhos terão as mínimas chances de se apropriarem das ciências, das artes e da reflexão filosófica. Não estamos caindo no idealismo de acreditar que, ainda no capitalismo, todas as escolas e universidades poderão abraçar plenamente o compromisso em socializar os conhecimentos elaborados nessas áreas. Todavia, também não caímos no imobilismo que afirma que nada pode ser feito. Entendemos que é possível e de extrema relevância a defesa dos conhecimentos científicos em todos os níveis da educação para a promoção intelectual e crítica dos alunos. Na mesma vertente, retomando as ideias de Vigotski e Saviani, Martins (2016) menciona que:

Tanto Vigotski quanto
Saviani postulam que às
características biológicas
asseguradas pela evolução
da espécie são acrescidas
outras, produzidas na
história de cada indivíduo
singular por decorrência
da vida social. Tais
características seriam,
então, próprias ao
desenvolvimento do que
Vigotski denominou de
funções psíquicas
superiores. Tais autores
consideram que o
desenvolvimento do
psiquismo humano e suas
propriedades não
resultam de uma
complexificação natural
evolutiva, mas, da própria
formação cultural dos
indivíduos (MARTINS,
2016, p. 54).

Nessa perspectiva, os elementos culturais devem constituir os conteúdos escolares haja vista serem estes os componentes educacionais que possibilitam o alargamento das funções psicológicas superiores e o desenvolvimento das habilidades sociais, humanas. Seguindo o mesmo raciocínio só há desenvolvimento quando a criança aprende, quando se apropria de um novo conceito científico.

Retomando o exemplo de Oxana Malaya, percebemos que a genética não foi suficiente para o desenvolvimento qualitativo humano ao longo dos anos. Mesmo que a sua constituição biológica cerebral, neurológica possuía elementos com possibilidades de progresso, as ausências do contato humano, das relações sociais e da apropriação da cultura humana, favoreceram um empobrecimento intelectual, ou seja, afetou as suas capacidades de pensamento e linguagem.

Esta história real demonstra que o desenvolvimento depende da aprendizagem, que requer a atividade de um ser humano no processo da educação escolar. Cabe lembrar que este ser humano se constitui com a apropriação da cultura humana em seu sentido amplo, para manifestar a sua própria humanidade. Dito de outra forma, o ser humano se desenvolve nas relações sociais. Assim como as características genéticas são transmitidas geneticamente de uma geração a outra, os constituintes sociais são transmitidos socialmente pelas gerações.

Martins (2013) ressalta o papel social da educação escolar, dos conteúdos que contribuem para o desenvolvimento das funções psicológicas ao afirmar que:

A defesa do ensino escolar voltado à transmissão dos conhecimentos científicos, não cotidianos, sobejamente defendido pela pedagogia históricocrítica, foi igualmente advogada por Vygotski (2001), para quem a formação de conceitos reorganiza todas as funções psicológicas, ou seja, requalifica o sistema psíquico em sua totalidade. Conforme o autor, ao requalificar as funções psíquicas é que a aprendizagem escolar cumpre uma de suas principais funções - incidir na personalidade dos indivíduos, haja vista que nela sintetizam-se as 
propriedades

culturalmente formadas que configuram a maneira de ser de cada sujeito particular. (MARTINS, 2013, p.136, grifos nossos.)

Esse posicionamento reforça o nosso entendimento de que os conteúdos que enriquecem mentalmente são os elementos culturais resultantes de investigações profundas acerca da realidade objetiva, como é o caso da ciência. "O homem definitivamente formado possui já todas as propriedades biológicas necessárias ao seu desenvolvimento sóciohistórico ilimitado" (LEONTIEV, 2004, p. 281-282). Por outras palavras, a produção e desenvolvimento da cultura humana são determinados pelas apropriações significativas, atividades sociais, intencionais e não biológicas, naturais.

O cérebro não é um sistema de funções psíquicas imutáveis. Segundo Vigotski (2001) e Leontiev (2004), as funções psicológicas superiores são desenvolvidas a partir das apropriações individuais adquiridas dentro dos processos sociais, da coletividade humana. Sobre a mutabilidade e os condicionantes históricosociais das modificações qualitativas da consciência (psiquismo), podemos afirmar que:

\footnotetext{
A consciência humana não é uma coisa imutável. [...] Portanto, devemos considerar a consciência (o psiquismo) no seu devir e no seu desenvolvimento, na sua dependência essencial do modo de vida, que é determinado pelas relações sociais existentes e pelo lugar que o indivíduo considerado ocupa nestas relações. [...] Visto que as condições sociais da existência dos homens se desenvolvem por modificações qualitativas e não apenas quantitativas, o psiquismo humano, a consciência humana, transforma-se igualmente de maneira qualitativa no decurso do desenvolvimento histórico e social (LEONTIEV, 2004, p.95).
}

Estas palavras são relevantes para a compreensão de que as relações sociais determinam o grau de transformação da consciência. Nossa intenção não é discorrer sobre a formação e desenvolvimento da consciência (psiquismo), mas a compreensão de que ela evolui histórica e socialmente, progressivamente, mediante a apreensão dos conhecimentos científicos, artísticos e filosóficos em suas formas mais elaboradas.

Em decorrência das apropriações e desenvolvimento das funções psíquicas superiores, o homem se transforma em sujeito sócio-histórico e, com isso, torna-se capaz de produzir cultura. Por isso, enfatizamos que na educação o professor deve investir em planejamento, conteúdos e método que sejam favoráveis a capacidade consciente dos alunos, o avanço da compreensão dos conceitos espontâneos, cotidianos, para avançar até as noções científicas, mais elaboradas.

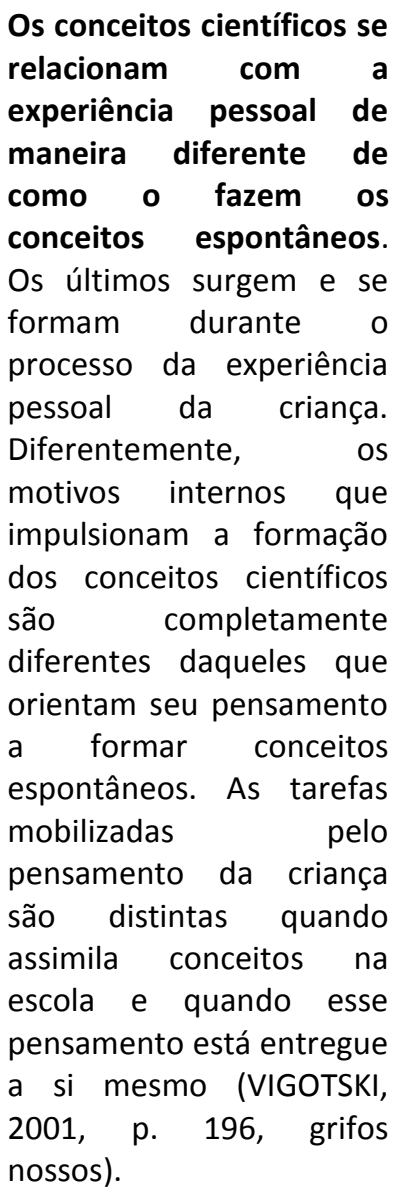

Quando a criança entra em contato com os conceitos científicos precisa raciocinar, avaliar, estimular a atividade de suas capacidades psicológicas superiores para entender e assimilar as informações. Esse exercício intencional contribui para o desenvolvimento do psiquismo 
entendendo que exige uma análise reflexiva mais elaborada do que no caso dos conceitos espontâneos que, conforme o próprio nome sugere, podem ser apreendidos de maneira simples a partir das experiências habituais. 0 processo de desenvolvimento intelectual mediante os conceitos científicos exige atividades cerebrais específicas e mais complexas do que as requeridas pelos espontâneos, provendo uma diferenciação no grau de elevação intelectual durante o processo de aprendizagem.

Mediante o exposto, entendemos que, para uma educação desenvolvente, faz-se imprescindível a apreensão dos conteúdos do mesmo modo desenvolventes (MARTINS, 2013, 2016). Por isso, a pedagogia histórico-crítica e a teoria histórico-cultural defendem que a função social do professor é a transmissão crítica, histórica e materialista dos conhecimentos em suas formas mais desenvolvidas, incluindo aqui, os conhecimentos científicos.

\section{CONSIDERAÇÕES FINAIS}

Os pressupostos apresentados permitem compreender que o propósito da educação para a teoria histórico-cultural e a pedagogia históricocrítica é elevar o nível intelectual e cultural do aluno, promover a mudança da concepção de mundo e o desenvolvimento da mente de maneira crítica e reflexiva. Entendemos que as ciências são fundamentais para que na educação escolar os alunos possam desenvolver as bases para uma compreensão não epidérmica da realidade natural e social.

Para desenvolver nosso argumento, partimos do processo de autoconstrução humana a partir dos atos de trabalho e foi possível, dessa forma, apreender a função social das ciências. 0 conhecimento científico será responsável por compreender a realidade natural ou social, da maneira mais correta e aproximada possível. É importante destacar a perspectiva ontológica que está na natureza do conhecimento científico, ou seja, o ímpeto da subjetividade não lucubrar e nem fantasiar sobre o objeto, mas postar-se de modo a compreendê-lo como ele é em seu movimento e em sua essência próprios.

A partir disso, foi possível entender que o que permite $o$ desenvolvimento cultural da criança, do pensamento e formação de conceitos científicos é a apropriação dos conhecimentos, valores, costumes, cultura etc. que foram produzidos historicamente. Cabe à educação escolar promover a sistematização e socialização desta apropriação de modo tal que sobreponha o conhecimento espontâneo.

Também deixamos claro que entendemos não ser possível, ainda no modo de produção capitalista, todas as escolas e universidades abraçarem plenamente a tarefa educativa em socializar os conhecimentos elaborados. Todavia, também não somos imobilistas, ou seja, não acreditamos que nada pode ser feito. Defendemos a explicitação do que é a ciência, bem como a sua urgente e necessária transmissão na educação escolar a partir de uma postura crítica, ontológica, histórica e materialista.

Precisamos dos conhecimentos científicos para o desenvolvimento das faculdades mentais que acrescentam a possibilidade de formação de conceitos, e, destes, para o enriquecimento cultural e produção de conhecimento científico, que, por sua vez, proporciona a continuidade do processo educativo com vistas a formação/transformação do homem concreto. Concreto aqui compreendido quanto sujeito sócio-histórico, capaz de produzir cultura, apreender o social, elaborar suas próprias críticas, avaliar o seu real papel e transformar a si mesmo e a sociedade na qual está inserido.

A educação escolar e a tarefa docente implicam sempre uma reflexão essencial: ou a defesa integral do ser humano ou a sua deturpação a partir dos interesses mercadológicos. A defesa das ciências e do desenvolvimento dos alunos é a opção daqueles que optaram pelo humanismo crítico e autêntico.

\section{REFERÊNCIAS}

DUARTE, N. A Pedagogia Histórico-crítica e a Formação da Individualidade para si. Germinal: Marxismo e Educação em Debate, Salvador, v. 5, n. 2, p. 59-72, dez. 2013. Disponível em: https://doi.org/10.9771/gmed.v5i2.9699 . Acesso em: 08 nov. 2020.

DUARTE, N. Os conteúdos escolares e a ressureição dos mortos: contribuição à teoria histórico-crítica do currículo. Campinas, SP: Autores Associados, 2016.

DUARTE, N. Entrevista com o professor Dermeval Saviani; Pedagogia Histórico-Crítica na atualidade. Colloquium Humanarum, Presidente Prudente, v. 16, n. 2, p. 4-12, abr./jun., 2019. Disponível 
https://revistas.unoeste.br/index.php/ch/article/ view/3121/2765. Acesso em: 08 nov. 2020. https://doi.org/10.5747/ch.2019.v16.n2.h414

LEONTIEV, A. N. O Desenvolvimento do

Psiquismo. São Paulo: Centauro, 2004.

LUKÁCS, G. Para uma ontologia do ser social - II. São Paulo: Boitempo, 2013.

MARTINS, L. M. Os fundamentos psicológicos da pedagogia histórico-crítica e os fundamentos pedagógicos da psicologia histórico-cultural. Germinal: Marxismo e Educação em Debate, Salvador, v. 5, n. 2, p. 130-143, dez. 2013. Disponível em: http://dx.doi.org/10.9771/gmed.v5i2.9705.

Acesso em: 08 nov. 2020. .

MARTINS, L. M. Fundamentos da Psicologia Histórico-Cultural e da Pedagogia Históricocrítica. In: MESQUITA, A. M.; FANTIN, F. C. B.; ASBHAR, F. F. S. (org.). Currículo comum para o ensino fundamental Municipal de Bauru. Bauru: Secretaria Municipal de Educação, 2016. p. 41-79. Disponivel em: https://tinyurl.com/y7r7l8my. Acesso em: 08 nov. 2020.

ROSSI, R.; ROSSI, A. S. Escola e conhecimento: em defesa dos clássicos e da crítica. Colloquium Humanarum, Presidente Prudente, v. 16, n. 3, p. 144-155, jul./set. 2019. Disponível em: http://journal.unoeste.br/index.php/ch/article/vi ew/3203. Acesso em: 08 nov. 2020. https://doi.org/10.5747/ch.2019.v16.n3.h439

SAVIANI, D. Pedagogia histórico-crítica: primeiras aproximações. 11. ed. rev. Campinas, SP: Autores Associados, 2011.

VYGOTSKY, L. S. A Formação Social da Mente. 4. ed. São Paulo: Martins Fontes, 1991.

VIGOTSKY, L. S. Obras escogidas.. Madrid: Visor, 2001. Tomo II. 